OPEN ACCESS

Edited by:

Yawei Zhang,

Yale University, United States

Reviewed by:

Francesca Gorini,

National Research Council (CNR), Italy Ibrahim Abdelmageed Ginawi,

Ministry of Health, Saudi Arabia

*Correspondence:

Wuqing Huang

wuqing.huang@med.lu.se

Specialty section:

This article was submitted to

Cancer Epidemiology and Prevention,

a section of the journal

Frontiers in Oncology

Received: 13 March 2020

Accepted: 29 June 2020

Published: 04 August 2020

Citation:

Huang W, Sundquist $K$, Sundquist J and Ji J (2020) Risk of Being Born

Preterm in Offspring of Cancer Survivors: A National Cohort Study.

Front. Oncol. 10:1352.

doi: $10.3389 /$ fonc.2020.01352

\section{Risk of Being Born Preterm in Offspring of Cancer Survivors: A National Cohort Study}

\author{
Wuqing Huang ${ }^{1 *}$, Kristina Sundquist ${ }^{1,2,3}$, Jan Sundquist ${ }^{1,2,3}$ and Jianguang $\mathrm{Ji}^{1}$ \\ ${ }^{1}$ Center for Primary Health Care Research, Lund University/Region Skåne, Malmö, Sweden, ${ }^{2}$ Department of Family Medicine \\ and Community Health, Department of Population Health Science and Policy, Icahn School of Medicine at Mount Sinai, \\ New York, NY, United States, ${ }^{3}$ Department of Functional Pathology, Center for Community-Based Healthcare Research and \\ Education (CoHRE), School of Medicine, Shimane University, Matsue, Japan
}

Background: With the increased number of cancer survivors, it is necessary to explore the effect of cancer and its treatments on pregnancy outcomes, such as preterm birth, which seriously endangers the health of offspring. We aimed to explore the risk of being born preterm among offspring of cancer survivors.

Materials and Methods: This is a retrospective cohort study. All singleton live births between 1973 and 2014 in Sweden with information of birth outcomes were retrieved from the Swedish Medical Birth Register. By linking to several Swedish registers, we identified all parents of children and parental cancer diagnosis. Logistic regression was used to estimate odds ratios and 95\% confidence intervals.

Results: As compared to the children without parental cancer, the risk of being born preterm was significantly higher among children of overall female cancer survivors born after cancer diagnosis with an adjusted OR of 1.48 (95 Cl\% =1.39-1.59), in particular those diagnosed with childhood cancer and cancer in female genital organs. Besides, the risk might continuously decline with time at the first 8 years after maternal diagnosis. A higher risk of being born preterm was found among offspring of male survivors diagnosed with central nervous system cancer (Adjusted $O R=1.26,95 \% \mathrm{Cl}=1.04-1.53$ ).

Conclusions: Our study provides evidence for a higher risk of being born preterm among children of female cancer survivors and male survivors with central nervous system tumor, as well as indicates that the effect on female reproductive system from cancer and related-treatments might decline with time.

Keywords: preterm birth, cancer, survivorship, offspring, epidemiology

\section{BACKGROUND}

With the great development of cancer therapies and cancer screening, the overall cancer survival rate has improved during recent decades. For example, in America, the statistical evidence reported in 2016 showed that over 15.5 million cancer survivors were alive on January 1, 2016 and the number is expected to increase to 20 million by January 1, 2026 (1); Globally, 33 million individuals with a history of cancer had lived for over 5 years after the diagnosis in 2012 (2). This drives further studies about long-term effect or "late effect" caused by cancer itself and relevant treatments, including chemotherapy and radiotherapy (3). There is growing 
evidence that both females and males with a history of cancer were less likely to have a child compared to the general population, besides female survivors may suffer a higher risk of complications during pregnancy and adverse pregnancy outcomes (4-23). It indicates that cancer survivors are at an increased risk of disorders in the reproductive system.

Preterm birth (PTB) is the dominating cause of neonatal death with an estimated number of 1.1 million infants dying from complications of PTB each year (24). Furthermore, PTB is the second most common cause of death among children under 5 years of age around the world, and children with PTB suffer a higher risk of long-term growth damage and morbidity, such as neurologic and developmental disabilities (24). In 2008, the rates of PTB across Europe ranged from 5.5 to $11.1 \%$ for all live births and from 4.3 to $8.7 \%$ for singleton birth (25). In Sweden, the prevalence of PTB has been relatively stable during recent decades with an estimated rate of around $6 \%$.

The objectives of our study are (1) to examine whether the risk of being born preterm is higher among offspring of cancer survivors as compared with offspring from healthy parents, (2) to explore whether the incidence of PTB might be negatively associated with the time interval between the diagnosis of parental cancer and the delivery of children based on the hypothesis that the adverse effect in the genital system and germ cells caused by chemotherapy or radiotherapy might be recovered gradually, and (3) to examine whether the observed effect on PTB is heterogeneous in relation to various cancer types.

\section{MATERIALS AND METHODS}

\section{Study Population}

All singleton live births between 1973 and 2014 in Sweden were included in the Swedish Medical Birth Register. By linking to the Swedish Multiple Generation Register and Swedish Cancer Registry, we could identify the parents of these children and obtain information about cancer diagnosis for parents. The Swedish Medical Birth Register was founded in 1973, which consisted of information related to pregnancy and childbirth (26). The Swedish Multi-Generation Register was created in 1932 where all individuals were linked to their first-degree relatives. The Swedish Cancer Registry was created in 1958 and used the 7 th version of the International Classification of Diseases (ICD) code to record cancer diagnosis during the study period. As it is compulsory for clinicians, pathologists, and cytologists to report all newly diagnosed cancers to the Swedish Cancer Register, this Register is estimated to cover $90 \%$ newly-diagnosed cancer cases in Sweden (27).

A total of 12,583 children were identified with a maternal cancer and delivered 1 year after maternal cancer diagnosis and 13,253 with a paternal cancer diagnosis, which were the targeted population in this study. All childbirths born within 1 year after parental cancer diagnosis were excluded to make sure that the child was conceived after maternal or paternal cancer diagnosis. A total of 35,07,481 children were born in parents without cancer history, which is the reference group in the current study.

To control unmeasured confounding factors, two types of cosibling analyses were further performed to compare differentially exposed siblings. The first one was to examine PTB in children, who were delivered after the diagnosis of cancer in their parents, and compared with their siblings who were delivered before the diagnosis of parental cancer. This analysis aimed to control unmeasured confounding factors shared in the siblings. Of targeted children of female survivors, 2,027 pairs of siblings were used in the first co-sibling study. It should be noted that female survivors might have multiple childbirths both before and after the diagnosis of cancer, thus these 2,027 pairs include 2,520 children born before maternal cancer diagnosis and 3,002 siblings born after maternal cancer diagnosis. Among offspring of male survivors, a total of 2,227 pairs of siblings were used in the this co-sibling study, including 3,765 children born before paternal cancer diagnosis and 4,723 siblings born after paternal cancer diagnosis. The second one was to examine PTB among children of cancer survivors who have more than one child after their diagnosis of cancer, and using the first child after parental cancer as the reference. This analysis aimed to explore whether PTB might be negatively associated with the time interval between the diagnosis of parental cancer and delivery of children. A total of 3,673 pairs in female survivors and 3,737 pairs in male survivors were used in the second co-sibling study.

The Ethics Committee at Lund University approved (February 6,2013 ) this nationwide cohort study (Dnr 2012/795). Through advertisements in the major newspapers people could choose to opt out before the project database were constructed.

\section{Study Outcomes}

Preterm birth was defined as a live birth occurring at less than 37 full weeks ( $<37$ weeks) of gestation, early preterm birth as less than 32 weeks ( $<32$ weeks) and extremely preterm birth as less than 28 weeks ( $<28$ weeks) (24). Gestational age at birth was calculated by maternal report of last menstrual period in the 1970s and ultrasound estimation in the 1980s and later in Swedish Medical Birth Registry.

\section{Independent Variables}

As shown in Table 1, the independent variables included child gender, year of childbirth, maternal age at birth, paternal age at birth, maternal age at diagnosis of cancer, paternal age at diagnosis of cancer, and the types of cancer in parents.

Child gender was modeled as either male or female. Year of child birth was modeled as $<1990$ or $\geq 1990$. Age of parents at birth was modeled as $<25,25-29$, and $\geq 30$ years. Age at diagnosis of cancer in the parents was modeled as childhood cancer (age 0-14), adolescent and young adult cancer (age 15-29) and adult cancer (age >29). Cancer diagnosis was categorized into cancers in the digestive system (including upper aerodigestive tract, esophagus, salivary gland, stomach, small intestine, colon, rectum, anus, liver, and pancreas), hematological malignancy (including non-Hodgkin's lymphoma, Hodgkin's disease, myeloma, and leukemia), cancers in the male genital organs (including prostate, testis, and other male genital), cancers in the female genital organs (including breast, cervix, ovary, endometrium, uterus, and other female genital), and other cancers (including nose, lung, eye, breast, thyroid gland, and endocrine glands, bladder, kidney, bone, and connective tissue). 
TABLE 1 | Sociodemographic and clinical characteristics among offspring of female and male cancer survivors and controls.

\begin{tabular}{|c|c|c|c|c|c|c|}
\hline \multirow[t]{2}{*}{ Variables } & \multicolumn{2}{|c|}{$\begin{array}{l}\text { Offspring of female } \\
\text { cancer survivors }\end{array}$} & \multicolumn{2}{|c|}{$\begin{array}{l}\text { Offspring of male } \\
\text { cancer survivors }\end{array}$} & \multicolumn{2}{|c|}{$\begin{array}{l}\text { Offspring of parents both } \\
\text { without cancer history }\end{array}$} \\
\hline & $\begin{array}{c}\text { No. of } \\
\text { individuals }\end{array}$ & $\begin{array}{l}\text { No. of preterm } \\
\text { birth, } N(\%)\end{array}$ & $\begin{array}{c}\text { No. of } \\
\text { individuals }\end{array}$ & $\begin{array}{l}\text { No. of preterm } \\
\text { birth, } N(\%)\end{array}$ & $\begin{array}{c}\text { No. of } \\
\text { individuals }\end{array}$ & $\begin{array}{c}\text { No. of preterm } \\
\text { birth, } N(\%)\end{array}$ \\
\hline Overall & 12,583 & $913(7.26)$ & 13,253 & $672(5.07)$ & $35,07,481$ & 1,76,072 (5.02) \\
\hline \multicolumn{7}{|l|}{ Gender of offspring } \\
\hline Male & 6,509 & $456(7.01)$ & 6,843 & $347(5.07)$ & $18,03,060$ & 96,107 (5.33) \\
\hline Female & 6,074 & 457 (7.52) & 6,410 & $325(5.07)$ & $17,04,421$ & 79,965 (4.69) \\
\hline \multicolumn{7}{|l|}{ Year of childbirth } \\
\hline$<1990$ & 3,289 & $220(6.69)$ & 3,192 & $175(5.48)$ & $12,65,651$ & $66,143(5.23)$ \\
\hline$\geq 1990$ & 9,294 & $693(7.46)$ & 10,061 & 497 (4.94) & $22,41,830$ & 1,09,929 (4.90) \\
\hline \multicolumn{7}{|l|}{ Maternal age at birth } \\
\hline$<30$ & 4,039 & $313(7.75)$ & 4,831 & $242(5.01)$ & $19,33,283$ & 98,389 (5.09) \\
\hline $30-34$ & 4,621 & $311(6.73)$ & 4,712 & $214(4.54)$ & $10,33,517$ & $47,893(4.63)$ \\
\hline$\geq 35$ & 3,923 & $289(7.37)$ & 3,710 & $216(5.82)$ & $5,40,681$ & $29,790(5.51)$ \\
\hline \multicolumn{7}{|l|}{ Paternal age at birth } \\
\hline$<30$ & 4,107 & $297(7.23)$ & 2,474 & $119(4.81)$ & $13,24,997$ & $70,502(5.32)$ \\
\hline $30-34$ & 4,107 & $297(7.23)$ & 4,090 & $205(5.01)$ & $11,48,367$ & $53,470(4.66)$ \\
\hline$\geq 35$ & 5,531 & 368 (6.65) & 6,689 & $348(5.20)$ & $10,34,117$ & $52,100(5.04)$ \\
\hline \multicolumn{7}{|l|}{ Age at diagnosis of cancer } \\
\hline Childhood cancer (0-14) & 1,956 & $154(7.87)$ & 1,516 & $81(5.34)$ & & \\
\hline Adolescence and young adult cancer (15-29) & 8,130 & $562(6.91)$ & 7,413 & $374(5.05)$ & & \\
\hline Adult cancer (>29) & 2,497 & $197(7.89)$ & 4,324 & $217(5.02)$ & & \\
\hline \multicolumn{7}{|l|}{ Types of cancer } \\
\hline Digestive system & 902 & $48(5.32)$ & 1,160 & $63(5.43)$ & & \\
\hline Central nervous system & 1,450 & $112(7.72)$ & 1,756 & $109(6.21)$ & & \\
\hline Hematological malignancy & 1,982 & $143(7.21)$ & 2,438 & $118(4.84)$ & & \\
\hline Skin cancer and melanoma & 2,635 & $163(6.19)$ & 1,948 & $106(5.44)$ & & \\
\hline Male genital organs & - & - & 3,069 & $147(4.79)$ & & \\
\hline Female genital organs & 2,108 & $242(11.48)$ & - & - & & \\
\hline Others & 4,121 & 260 (6.31) & 3,089 & $140(4.53)$ & & \\
\hline
\end{tabular}

\section{Statistical Analysis}

Unconditional logistic regression was used to estimate odds ratios (OR) and 95\% confidence intervals (95\% CI) for the association between PTB and parental cancer diagnosis by using offspring without parental cancer history as the reference category. Analyses were further stratified by gender of offspring, age at diagnosis of cancer in parents, year of childbirth and types of cancer in the parents. Given that in-vitro fertilization was first adopted in 1982 and very rare before 1990 in Sweden (28), stratified analysis was performed to see whether the risk of PTB among offspring of cancer survivors might be varied for those born before 1990 and those after 1990. Conditional logistic regression was used for co-sibling study design to estimate OR and 95\% CI for the association between PTB and paternal cancer diagnosis. Both analyses were conducted, firstly unadjusted, and then adjusted for year of childbirth and parental age at birth.

Besides, multivariate logistic regression using restricted cubic splines with 4 knots was built to investigate how the impact on PTB risk changed with the increase of time interval between parental cancer diagnosis and childbirth among children of cancer survivors, adjusting for year of childbirth and parental age at birth.

Logistic regression analyses were performed using SAS version 9.3 (SAS Institute, Cary, NC), and restricted cubic splines analysis was performed in $\mathrm{R}$ package.

\section{RESULTS}

We present the basic characteristics of children of cancer survivors and the controls in Table 1. As shown in Table 1, a total of 913 (7.26\%) PTBs were noted from 12,583 offspring of female cancer survivors, and 672 (5.07\%) PTBs from 13,253 offspring of male cancer survivors. As for the controls, 1,76,072 (5.02\%) PTBs were identified from 35,07,481 children.

Children born after maternal cancer diagnosis suffered a significantly increased risk of PTB when compared with the reference group (Table 2). The positive association remained similar after adjusting for year of childbirth and parental age at birth with an adjusted OR of 1.48 (95\% CI 1.39-1.59). The 
TABLE 2 | Odd ratios (ORs) and 95\% confidence intervals (Cls) of preterm birth among offspring of female and male cancer survivors compared with controls.

\begin{tabular}{|c|c|c|c|c|c|c|c|c|}
\hline \multirow[t]{2}{*}{ Variables } & \multicolumn{4}{|c|}{ Female cancer survivors } & \multicolumn{4}{|c|}{ Male cancer survivors } \\
\hline & Crude OR & $95 \% \mathrm{Cl}$ & Adjusted OR ${ }^{a}$ & $95 \% \mathrm{Cl}$ & Crude OR & $95 \% \mathrm{Cl}$ & Adjusted OR ${ }^{a}$ & $95 \% \mathrm{Cl}$ \\
\hline Overall & 1.48 & $1.39-1.59$ & 1.48 & $1.39-1.59$ & 1.01 & $0.94-1.09$ & 1.02 & $0.94-1.10$ \\
\hline \multicolumn{9}{|l|}{ Gender of offspring } \\
\hline Male & 1.34 & $1.22-1.47$ & 1.34 & $1.22-1.48$ & 0.95 & $0.85-1.06$ & 0.96 & $0.86-1.07$ \\
\hline Female & 1.65 & $1.50-1.82$ & 1.64 & $1.49-1.81$ & 1.09 & $0.97-1.22$ & 1.09 & $0.97-1.22$ \\
\hline \multicolumn{9}{|l|}{ Year of childbirth } \\
\hline$<1990$ & 1.36 & $1.18-1.56$ & 1.32 & $1.15-1.51$ & 1.10 & $0.95-1.28$ & 1.07 & $0.92-1.25$ \\
\hline$\geq 1990$ & 1.53 & $1.42-1.65$ & 1.54 & $1.42-1.66$ & 0.98 & $0.90-1.08$ & 1.00 & $0.92-1.10$ \\
\hline \multicolumn{9}{|l|}{ Age at diagnosis of cancer } \\
\hline Childhood cancer (0-14) & 1.63 & $1.38-1.92$ & 1.64 & $1.39-1.93$ & 1.07 & $0.86-1.34$ & 1.08 & $0.87-1.35$ \\
\hline Adolescence and young adult cancer (15-29) & 1.41 & $1.29-1.53$ & 1.43 & $1.31-1.56$ & 1.00 & $0.91-1.12$ & 1.02 & $0.92-1.14$ \\
\hline Adult cancer (>29) & 1.63 & $1.41-1.89$ & 1.53 & $1.33-1.77$ & 1.00 & $0.87-1.15$ & 0.99 & $0.86-1.13$ \\
\hline \multicolumn{9}{|l|}{ Types of cancer } \\
\hline Digestive system & 1.07 & $0.80-1.42$ & 1.06 & $0.79-1.42$ & 1.09 & $0.85-1.41$ & 1.09 & $0.84-1.40$ \\
\hline Central nervous system & 1.59 & $1.31-1.93$ & 1.60 & $1.32-1.94$ & 1.25 & $1.03-1.52$ & 1.26 & $1.04-1.53$ \\
\hline Hematological system & 1.48 & $1.24-1.75$ & 1.50 & $1.27-1.78$ & 0.96 & $0.80-1.16$ & 0.97 & $0.81-1.17$ \\
\hline Skin cancer and melanoma & 1.25 & $1.07-1.46$ & 1.24 & $1.06-1.46$ & 1.09 & $0.90-1.33$ & 1.09 & $0.90-1.33$ \\
\hline Male genital organs & - & - & - & - & 0.95 & $0.81-1.13$ & 0.97 & $0.82-1.14$ \\
\hline Female genital organs & 2.45 & $2.15-2.81$ & 2.42 & $2.12-2.77$ & - & - & - & - \\
\hline Others & 1.28 & $1.12-1.45$ & 1.26 & $1.11-1.43$ & 0.90 & $0.76-1.07$ & 0.90 & $0.76-1.07$ \\
\hline
\end{tabular}

${ }^{a}$ Adjusted for year of childbirth, age of father at birth, and age of mother at birth.

association was slightly stronger in girls or children born after 1990. The risk of PTB was highest among children whose mothers were diagnosed with childhood cancer (Adjusted $O R=1.64$, 95\% CI 1.39-1.93), and the risk was 1.43 (95\% CI 1.31-1.56) for children whose mothers were diagnosed with adolescent and young adult cancer and 1.53 (95\% CI 1.33-1.77) for children whose mothers were diagnosed with adult cancer. Except for maternal cancers in the digestive system, maternal diagnosis with other types of cancer was found to be related to the risk of offspring's PTB, especially survivors with maternal diagnosis of female genital cancer (Adjusted $O R=2.42,95 \% \mathrm{CI}=2.12-$ 2.77). A greater risk of very preterm and extremely preterm births was also found among offspring of female cancer survivors when compared to the controls (Supplementary Table 1). No significant association of PTB risk was observed with children of male cancer survivors. When the analyses were stratified by cancer sites in the father, a significantly increased OR was found among children whose fathers were diagnosed with central nervous system cancer (Adjusted $O R=1.26$, 95\% CI 1.041.53). As shown in Figure 1, among children of overall female survivors, the adjusted OR significantly decreased with the increase of time interval at the first 8 years after maternal diagnosis and then slightly increased in the following years $(P$ value for non-linear $=0.005$ ). But no significant non-linear or linear relationship was found in children of male survivors $(P$-value for non-linear $=0.151)$.

We present ORs and 95\% CI of PTB using co-sibling design in Table 3. After adjusting for potential confounders, no significant association was found between maternal or paternal cancer diagnosis and PTB risk when comparing siblings born before and after cancer diagnosis. For families with more than one childbirth after parental cancer, we found that the risk of PTB in the children born later was significantly lower as compared with the first child. The adjusted OR was 0.49 for children of female survivors (95\% CI $0.36-0.67$ ) and 0.49 for male survivors (95\% CI 0.35-0.67).

\section{DISCUSSION}

In this retrospective cohort study, which is to our knowledge the largest study on this topic so far, we found that the risk of PTB was significantly higher among children of female cancer survivors born after maternal cancer diagnosis, and the risk was even more predominant for mothers with a childhood cancer and with cancers in the female genital organs. Although the overall risk of PTB was similar among children of male cancer survivors as compared to the controls, the risk was significantly increased among children whose fathers were diagnosed with tumors in the nervous system. When compared with the first childbirth of survivors, the risk of PTB was significantly decreased among their siblings born later. Besides, in female survivors, we found the risk continuously declined at the first 8 years after diagnosis, suggesting that the adverse effect on the reproductive system might be recovered gradually. It is thus of high clinical relevance for those cancer survivors who plan to have a child.

Recently, a growing number of studies estimated the risk of PTB among children of female cancer survivors, which concurs with our results that children with maternal cancer diagnosis 


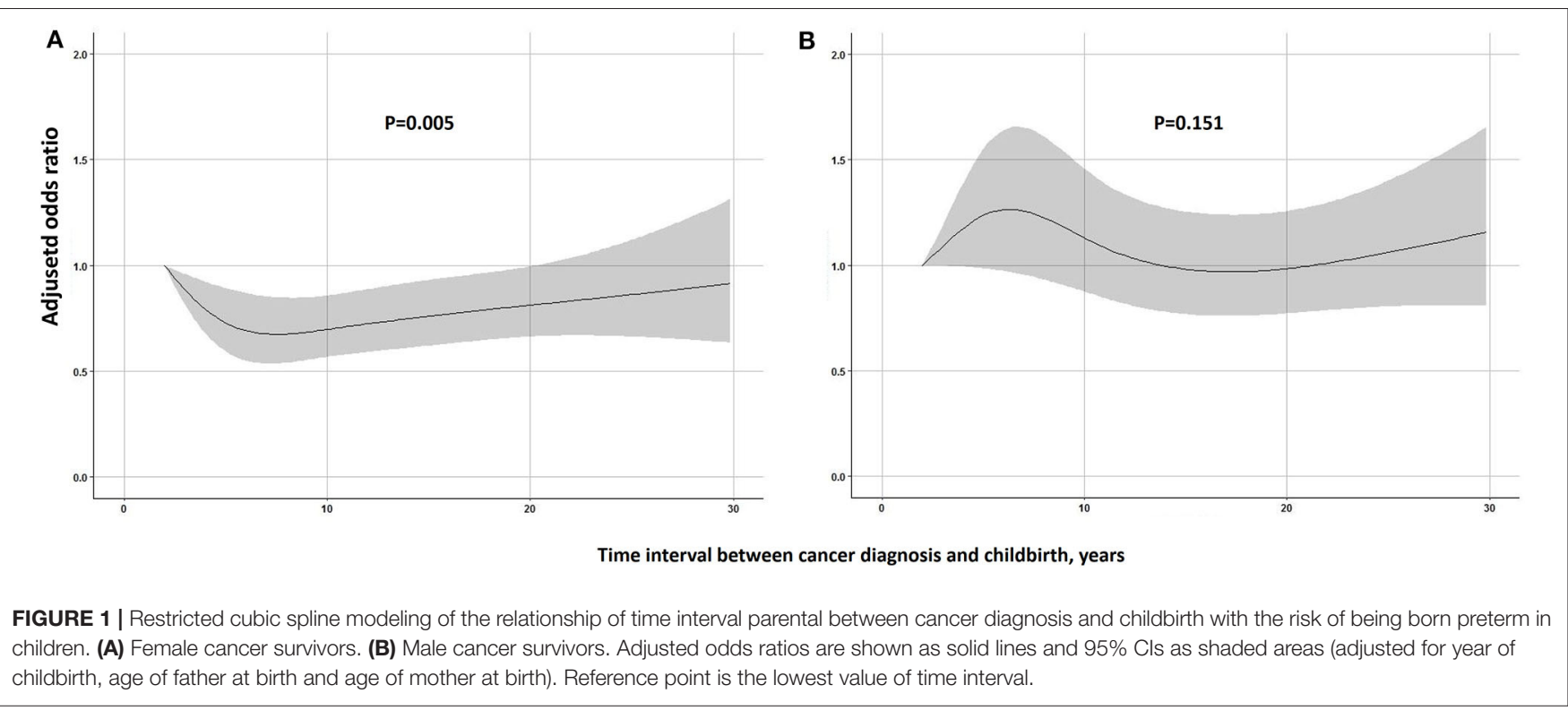

TABLE 3 | Odd ratios (ORs) and 95\% confidence intervals (Cls) of preterm birth among female and male cancer survivors using co-sibling design.

\begin{tabular}{|c|c|c|c|c|c|c|}
\hline Variables & No. of individuals & No. of preterm birth, $N(\%)$ & Crude OR & $95 \% \mathrm{Cl}$ & Adjusted OR ${ }^{a}$ & $95 \% \mathrm{Cl}$ \\
\hline \multicolumn{7}{|l|}{ Female cancer survivors } \\
\hline \multicolumn{7}{|c|}{ Comparison between siblings born before and after diagnosis } \\
\hline Offspring born after diagnosis & 2,520 & $192(7.62)$ & 1.43 & $1.12-1.83$ & 1.24 & $0.79-1.94$ \\
\hline \multicolumn{7}{|c|}{ Comparison between children after diagnosis } \\
\hline \multicolumn{7}{|l|}{ Male cancer survivors } \\
\hline \multicolumn{7}{|c|}{ Comparison between siblings born before and after diagnosis } \\
\hline Offspring born before diagnosis & 4,723 & $241(5.10)$ & 1.00 & - & 1.00 & - \\
\hline Offspring born after diagnosis & 3,765 & $186(4.94)$ & 0.82 & $0.63-1.07$ & 0.74 & $0.46-1.17$ \\
\hline \multicolumn{7}{|c|}{ Comparison between children after diagnosis } \\
\hline
\end{tabular}

${ }^{a}$ Adjusted for year of childbirth, age of father at birth, and age of mother at birth.

were at an increased risk of PTB but differed in terms of maternal cancer types (3-6, 11, 14, 19, 21, 29, 30). Evidence from Cancer Registries in three U.S. states found a higher risk of PTB among first child of female survivors diagnosed with cervical, invasive breast cancer and leukemia, but no association with brain, thyroid cancer, melanoma, and Hodgkin lymphoma (21). The data were consistent with our results and found a higher PTB risk associated with maternal cancer in the female genital organs. In addition, our study found an elevated risk of PTB irrespective of the age at diagnosis of maternal cancer, and the risk was even higher in childhood cancer survivors. Concordant with our study, the nationwide study in Finland found that children of childhood cancer survivors had a $62 \%$ increased risk and children of young adult cancer survivors had a $36 \%$ increased risk compared with children of maternal siblings
(11). A review targeting children of childhood, adolescent and young adult female cancer survivors showed that the rate of PTB was 1.5- to 2-fold higher in survivors compared with siblings or the general population (31), which suggests that age at diagnosis of maternal cancer had a different effect on the risk of PTB in their children. When we used co-sibling study design and compared with their siblings born before maternal cancer diagnosis, the association was not significant, suggesting that unmeasured familial factors might contribute to the observed association. However, we cannot exclude the possibility of falsenegative due to a limited number of sibling pairs leading to a wide confidence interval.

Plenty of evidence suggests that cancer treatments, including chemotherapy drugs, and/or radiation, have a detrimental effect on ovary and uterus, and malfunction of these organs plays a 
key role in developing PTB (32). Among the female reproductive organs, the ovary has been found to be most sensitive to chemotherapy and was also compromised by radiation (32). Previous studies summarized the adverse outcomes of cancer treatments as either acute ovarian failure or premature ovarian failure (32). The former one damages the growing follicles, which is temporary and reversible, and more frequently diagnosed among cancer survivors diagnosed at an older age (33). The latter form may develop among some childhood cancer survivors who retain some ovarian function for a period and then experience a gradual irreversible diminished ovary function (8). In addition, majority of childhood cancer survivors tended to give a birth after over 15 years from cancer diagnosis which might be the reason why offspring of childhood cancer survivors had a higher risk of PTB. Besides, animal studies also observed that radiosensitivity of ovarian follicles differs depending upon developmental stages (34). The uterus does not seem to be affected by chemotherapy drugs according to the current evidence, while uterine function was significantly damaged by radiation therapy through influencing the endometrium, myometrium, and vascular structures in the uterus, especially when cancer survivors were exposed to pelvic, spinal, and abdominal irradiation, which would be responsible for the higher risk of PTB among children of female reproductive system cancer (31).

The current study found no association between paternal cancer diagnosis and overall offspring's PTB risk. Three previous studies, targeting on first offspring among male cancer survivors, found no significant increased risk as well $(6,14,17)$. All of the previous studies were limited to Norway population and had partly overlapping data, additionally, the sample size was relatively smaller as compared to our study $(6,14,17)$. In this study, it was noteworthy that an elevated risk was found among offspring of male survivors diagnosed as central nervous system tumor, which was in line with our previous study in survivors of childhood or adolescent central nervous system tumor (35). It is interesting that evidence from National Cancer Institute's Surveillance, Epidemiology, and End Results (SEER) Program suggested that female partners of male central nervous system cancer survivors tended to suffer with preeclampsia during a pregnancy that was associated with $\operatorname{PTB}(7,36)$. Cranial irradiation is used alone or in combination with surgery and/or chemotherapy for central nervous system cancer which is able to affect hypothalamic-pituitary- adrenal and -gonadal axis that contributes to the decline of spermatogenetic quality $(37,38)$. Thus, the biological plausibility of paternal history with central nervous system cancer as a risk factor for preterm birth might be inferred through pregnancy complications or hypothalamicpituitary- adrenal and -gonadal axis.

It is worth mentioning that in female survivors, we found a significant higher risk of PTB among first child born after cancer diagnosis as compared to siblings born later. Besides, restricted cubic splines regression allowed us to flexibly model and visualize the relationship and found that the risk of being born preterm in offspring of female survivors continuously declined in the first 8 years after parental cancer diagnosis. Such data strongly supports our hypothesis that damages to the female genital system due to chemo- or radiotherapy might be recovered gradually. For male survivors, their children were not at a significant higher risk of being born preterm when compared to general population and no significant variation of the association was observed with time, but a lower risk was observed among second child or more when compared with the first child. It might, to some extent, be related to "healthy worker effect," i.e., only those male survivors who had a relatively good condition tended to have more than one child.

Some strengths of our study could be noted for this study. Firstly, to the best of our knowledge, this is the populationbased study with largest sample size to investigate the adverse outcome in offspring of cancer survivors, allowing us to examine the continuous association modeling by restricted cubic splines regression. Secondly, Swedish Multi-Generation Register makes co-sibling design available which helps to exclude residual confounding by unmeasured environmental and/or genetic factors shared by the siblings. Besides, parental age at pregnancy can be adjusted in current study, which is an important factor for risk of adverse pregnancy outcomes. Finally, compared to self-reported data, our study enabled to avoid recall bias by using register-based data. However, lack of information about detailed cancer treatment made it unavailable to explore the specific impact of different cancer treatment on pregnancy outcomes. Besides we did not get access to the information about in-vitro fertilization, which might affect the risk of PTB. Stratified analysis by birth year before 1990 or after 1990 suggested that in-vitro fertilization might play a small role for the observed association.

The present study found an increased risk of being born preterm among children of female cancer survivors, in particular among children whose mother was diagnosed with childhood cancer and cancer in the female genital organs. In addition, paternal cancer in the central nervous system was a risk factor of offspring's PTB. Notably, the risk of being born preterm might decline with time within the first 8 years after diagnosis in children of female survivors. Our findings underline the necessity for continued prenatal follow-up of pregnancies among female cancer survivors and spouses of male survivors with central nervous system tumor. They are highly recommended to care about the timing of having a child to minimize the impacts caused by cancer and its therapy.

\section{DATA AVAILABILITY STATEMENT}

The datasets analyzed in this article are not publicly available. Registry data used for the analysis presented in this study are available from the appropriate Swedish authorities [the Swedish National Board of Health and Welfare (https://www. socialstyrelsen.se/en) and Statistics Sweden (https://www.scb. se/en)], for researchers who meet the criteria for access to confidential data.

\section{ETHICS STATEMENT}

The studies involving human participants were reviewed and approved by the Ethics Committee at Lund University (Dnr 
2012/795). Written informed consent was not needed in this register-based study as all individual identification information was removed to preserve anonymity.

\section{AUTHOR CONTRIBUTIONS}

WH, JJ, KS, and JS were responsible for the study concept and design. JS, KS, and JJ obtained funding. KS and JS acquired the data. WH did the statistical analysis and drafted the manuscript. All authors revised it for important intellectual content.

\section{FUNDING}

This work was supported by grants awarded to JJ by the Swedish Research Council (2016-02373) and Cancerfonden (2017 CAN2017/340) and Crafoordska stiftelsen, to KS by the Swedish Research Council (K2012-70X-15428-08-3), to JS by the Swedish Council for Working Life and Social Research

\section{REFERENCES}

1. Miller KD, Siegel RL, Lin CC, Mariotto AB, Kramer JL, Rowland JH, et al. Cancer treatment and survivorship statistics, 2016. CA Cancer J Clin. (2016) 66:271-89. doi: 10.3322/caac.21349

2. Ferlay J, Soerjomataram I, Dikshit R, Eser S, Mathers C, Rebelo M, et al. Cancer incidence and mortality worldwide: sources, methods and major patterns in GLOBOCAN 2012. Int J Cancer. (2015) 136:E359-86. doi: $10.1002 /$ ijc. 29210

3. Galligan AJ. Childhood cancer survivorship and long-term outcomes. $A d v$ Pediatr. (2017) 64:133-69. doi: 10.1016/j.yapd.2017.03.014

4. Fossa SD, Magelssen H, Melve K, Jacobsen AB, Langmark F, Skjaerven R. Parenthood in survivors after adulthood cancer and perinatal health in their offspring: a preliminary report. J Natl Cancer Inst Monogr. (2005) 77-82. doi: 10.1093/jncimonographs/lgi019

5. Signorello LB, Cohen SS, Bosetti C, Stovall M, Kasper CE, Weathers RE, et al. Female survivors of childhood cancer: preterm birth and low birth weight among their children. J Natl Cancer Inst. (2006) 98:1453-61. doi: 10.1093/jnci/djj394

6. Magelssen H, Melve KK, Skjaerven R, Fossa SD. Parenthood probability and pregnancy outcome in patients with a cancer diagnosis during adolescence and young adulthood. Hum Reprod. (2008) 23:178-86. doi: 10.1093/humrep/dem362

7. Chow EJ, Kamineni A, Daling JR, Fraser A, Wiggins CL, Mineau GP, et al. Reproductive outcomes in male childhood cancer survivors: a linked cancer-birth registry analysis. Arch Pediatr Adolesc Med. (2009) 163:887-94. doi: 10.1001/archpediatrics.2009.111

8. Green DM, Sklar CA, Boice JD Jr, Mulvihill JJ, Whitton JA, Stovall M, et al. Ovarian failure and reproductive outcomes after childhood cancer treatment: results from the Childhood Cancer Survivor Study. J Clin Oncol. (2009) 27:2374-81. doi: 10.1200/JCO.2008.21.1839

9. Mueller BA, Chow EJ, Kamineni A, Daling JR, Fraser A, Wiggins $\mathrm{CL}$, et al. Pregnancy outcomes in female childhood and adolescent cancer survivors: a linked cancer-birth registry analysis. Arch Pediatr Adolesc Med. (2009) 163:879-86. doi: 10.1001/archpediatrics. 2009.112

10. Hudson MM. Reproductive outcomes for survivors of childhood cancer. Obstet Gynecol. (2010) 116:1171-83. doi: 10.1097/AOG.0b013e3181f $87 \mathrm{c} 4 \mathrm{~b}$

11. Madanat-Harjuoja LM, Malila N, Lahteenmaki PM, Boice JDJr, Gissler M, Dyba T. Preterm delivery among female survivors of childhood, adolescent and young adulthood cancer. Int J Cancer. (2010) 127:1669-79. doi: $10.1002 /$ ijc. 25157
(2007-1754), to JS, KS, and JJ by ALF funding from Region Skåne, and to WH by China Scholarship Council (Grant No. 201806380121). The funding agencies had no role in the design and conduct of the study, in the collection, analysis, and interpretation of the data, or in the preparation, review, or approval of the manuscript. The researchers were independent of the funding agencies.

\section{ACKNOWLEDGMENTS}

The authors wish to thank the CPF's science editor Patrick Reilly for his valuable comments on the text.

\section{SUPPLEMENTARY MATERIAL}

The Supplementary Material for this article can be found online at: https://www.frontiersin.org/articles/10.3389/fonc. 2020.01352/full\#supplementary-material

12. Hartman M, Liu J, Czene K, Miao H, Chia KS, Salim A, et al. Birth rates among female cancer survivors: a population-based cohort study in Sweden. Cancer. (2013) 119:1892-9. doi: 10.1002/cncr.27929

13. Sigman M. Introduction: cancer treatment and male fertility: effects of therapy and current and future management options. Fertil Steril. (2013) 100:1179. doi: 10.1016/j.fertnstert.2013.09.011

14. Stensheim H, Klungsoyr K, Skjaerven R, Grotmol T, Fossa SD. Birth outcomes among offspring of adult cancer survivors: a population-based study. Int J Cancer. (2013) 133:2696-705. doi: 10.1002/ijc.28292

15. Bates GE, Taub RN, West H. Fertility and cancer treatment. JAMA Oncol. (2016) 2:284. doi: 10.1001/jamaoncol.2015.4143

16. Chow EJ, Stratton KL, Leisenring WM, Oeffinger KC, Sklar CA, Donaldson SS, et al. Pregnancy after chemotherapy in male and female survivors of childhood cancer treated between 1970 and 1999: a report from the Childhood Cancer Survivor Study cohort. Lancet Oncol. (2016) 17:567-76. doi: 10.1016/S1470-2045(16)00086-3

17. Gunnes MW, Lie RT, Bjorge T, Ghaderi S, Ruud E, Syse A, et al. Reproduction and marriage among male survivors of cancer in childhood, adolescence and young adulthood: a national cohort study. Br J Cancer. (2016) 114:348-56. doi: 10.1038/bjc.2015.455

18. Tang SW, Liu J, Juay L, Czene K, Miao H, Salim A, et al. Birth rates among male cancer survivors and mortality rates among their offspring: a population-based study from Sweden. BMC Cancer. (2016) 16:196. doi: 10.1186/s12885-016-2236-y

19. Anderson C, Engel SM, Mersereau JE, Black KZ, Wood WA, Anders CK, et al. Birth outcomes among adolescent and young adult cancer survivors. JAMA Oncol. (2017) 3:1078-84. doi: 10.1001/jamaoncol.2017.0029

20. Armuand G, Skoog-Svanberg A, Bladh M, Sydsjo G. Reproductive patterns among childhood and adolescent cancer survivors in sweden: a population-based matched-cohort study. J Clin Oncol. (2017) 35:1577-83. doi: 10.1200/JCO.2016.71.0582

21. Hartnett KP, Ward KC, Kramer MR, Lash TL, Mertens AC, Spencer JB, et al. The risk of preterm birth and growth restriction in pregnancy after cancer. Int J Cancer. (2017) 141:2187-96. doi: 10.1002/ijc.30914

22. Nichols HB, Anderson C, Ruddy KJ, Black KZ, Luke B, Engel SM, et al. Childbirth after adolescent and young adult cancer: a population-based study. J Cancer Surviv. (2018) 12:592-600. doi: 10.1007/s11764-018-0695-7

23. Armuand G, Skoog Svanberg A, Bladh M, Sydsjo G. Adverse obstetric outcomes among female childhood and adolescent cancer survivors in Sweden: a population-based matched cohort study. Acta Obstet Gynecol Scand. (2019) 98:1603-11. doi: 10.1111/aogs.13690

24. Harrison MS, Goldenberg RL. Global burden of prematurity. Semin Fetal Neonatal Med. (2016) 21:74-9. doi: 10.1016/j.siny.2015.12.007 
25. Zeitlin J, Szamotulska K, Drewniak N, Mohangoo AD, Chalmers J, Sakkeus L, et al. Preterm birth time trends in Europe: a study of 19 countries. BJOG. (2013) 120:1356-65. doi: 10.1111/1471-0528.12281

26. Signorello LB, Mulvihill JJ, Green DM, Munro HM, Stovall M, Weathers $\mathrm{RE}$, et al. Stillbirth and neonatal death in relation to radiation exposure before conception: a retrospective cohort study. Lancet. (2010) 376:624-30. doi: 10.1016/S0140-6736(10)60752-0

27. Ji J, Sundquist K, Sundquist J, Hemminki K. Comparability of cancer identification among death registry, cancer registry and hospital discharge registry. Int J Cancer. (2012) 131:2085-93. doi: 10.1002/ijc.27462

28. Kallen B, Finnstrom O, Lindam A, Nilsson E, Nygren KG, Otterblad Olausson P. Trends in delivery and neonatal outcome after in vitro fertilization in Sweden: data for 25 years. Hum Reprod. (2010) 25:1026-34. doi: 10.1093/humrep/deq003

29. Shliakhtsitsava K, Romero SAD, Dewald SR, Su HI. Pregnancy and child health outcomes in pediatric and young adult leukemia and lymphoma survivors: a systematic review. Leuk Lymphoma. (2018) 59:381-97. doi: 10.1080/10428194.2017.1352097

30. van Dorp W, Haupt R, Anderson RA, Mulder RL, van den Heuvel-Eibrink MM, van Dulmen-den Broeder E, et al. Reproductive function and outcomes in female survivors of childhood, adolescent, and young adult cancer: a review. J Clin Oncol. (2018) 36:2169-80. doi: 10.1200/JCO.2017.76.3441

31. Teh WT, Stern C, Chander S, Hickey M. The impact of uterine radiation on subsequent fertility and pregnancy outcomes. Biomed Res Int. (2014) 2014:482968. doi: 10.1155/2014/482968

32. Oktem O, Kim SS, Selek U, Schatmann G, Urman B. Ovarian and uterine functions in female survivors of childhood cancers. Oncologist. (2018) 23:21424. doi: 10.1634/theoncologist.2017-0201

33. Letourneau JM, Ebbel EE, Katz PP, Oktay KH, McCulloch CE, Ai WZ, et al. Acute ovarian failure underestimates age-specific reproductive impairment for young women undergoing chemotherapy for cancer. Cancer. (2012) 118:1933-9. doi: 10.1002/cncr.26403

34. Adriaens I, Smitz J, Jacquet P. The current knowledge on radiosensitivity of ovarian follicle development stages. Hum Reprod Update. (2009) 15:359-77. doi: 10.1093/humupd/dmn063

35. Huang W, Sundquist K, Sundquist J, Ji J. Risk of being born preterm in offspring of survivors with childhood or adolescent central nervous system tumor in Sweden. Int J Cancer. (2020) 147:100-6. doi: 10.1002/ijc.32722

36. Davies EL, Bell JS, Bhattacharya S. Preeclampsia and preterm delivery: a population-based case-control study. Hypertens Pregnancy. (2016) 35:510-9. doi: 10.1080/10641955.2016.1190846

37. Muller J. Disturbance of pubertal development after cancer treatment. Best Pract Res Clin Endocrinol Metab. (2002) 16:91-103. doi: 10.1053/beem.2002.0183

38. Lebaron-Jacobs L, Wysocki J, Griffiths NM. Differential qualitative and temporal changes in the response of the hypothalamus-pituitary-adrenal axis in rats after localized or total-body irradiation. Radiat Res. (2004) 161:712-22. doi: $10.1667 / R R 3180$

Conflict of Interest: The authors declare that the research was conducted in the absence of any commercial or financial relationships that could be construed as a potential conflict of interest.

Copyright (C) 2020 Huang, Sundquist, Sundquist and Ji. This is an open-access article distributed under the terms of the Creative Commons Attribution License (CC BY). The use, distribution or reproduction in other forums is permitted, provided the original author(s) and the copyright owner(s) are credited and that the original publication in this journal is cited, in accordance with accepted academic practice. No use, distribution or reproduction is permitted which does not comply with these terms. 